\title{
Cactaceae em um fragmento florestal urbano de Vila Velha, Espírito Santo, Brasil
}

\author{
Cactaceae in an urban forest fragment of Vila Velha, Espírito Santo, Brazil
}

Weverson C. Cardoso ${ }^{1,2}{ }^{(1)} \bar{R}$, Rodrigo T. Valadares ${ }^{1}{ }^{(1)}$, Luciana D. Thomaz ${ }^{(1)}$ \& Valquíria F. Dutra ${ }^{(1)}$

1. Herbário VIES, Universidade Federal do Espírito Santo, Centro de Ciências Humanas e Naturais, Departamento de Ciências Biológicas, Vitória, Espírito Santo, Brasil

\section{Programa de Pós-Graduação em} Ciências Biológicas (Botânica), Museu Nacional, Universidade Federal do Rio de Janeiro, Rio de Janeiro, Rio de Janeiro, Brasil

\section{Palavras-chave}

Cactos. Flora do Espírito Santo. Floresta Atlântica. Leste do Brasil.

\section{Keywords \\ Cacti. The Espirito Santo Flora. Atlantic \\ Forest. Eastern Brazil.}

\section{Doi}

doi.org/10.33447/paubrasilia.v3i2.48

Recebido em: 03/07/2020

Aceite em: 03/08/2020

Editor responsável: Jaílson S. de Novais (UFSB)

ISSN: 2595-6752

\section{Resumo}

Cactaceae é uma família quase que exclusivamente endêmica do Novo Mundo. No estado do Espírito Santo, Brasil, a família é pouco amostrada e inventários florísticos de seus representantes são escassos. O objetivo deste trabalho foi realizar a flora das espécies de Cactaceae ocorrentes em um fragmento urbano antropizado na Floresta Atlântica no Espírito Santo. Foram realizadas excursões quinzenais no período entre agosto de 2011 e julho de 2012. Nove espécies de Cactaceae foram encontradas, pertencentes a sete gêneros. Três das espécies são endêmicas da Floresta Atlântica e duas são citadas como ameaçadas de extinção, uma delas registrada para o Espírito Santo pela primeira vez, após uma lacuna aproximada de um século. Nossos dados ressaltam a importância da conservação do fragmento florestal e a necessidade de estudos acerca da família em outras áreas do estado. Apresentamos uma chave taxonômica ilustrada, descrições, comentários sobre a taxonomia, distribuição geográfica e ecologia das espécies, além da conservação de suas populações na área.

\begin{abstract}
Cactaceae is almost exclusively endemic to the New World. In Espirito Santo State, the family is poorly sampled and floristic surveys of its representatives are scarce. The aim of this work was do the flora of Cactaceae species occurring in an urban anthropized Atlantic Forest fragment in the Espirito Santo State. Two weekly trips were made between August 2011 and July 2012. Nine species of Cactaceae belonging to seven genera were founded. Three species are endemic to the Atlantic Forest and two are cited as endangered, one of them registered for the Espirito Santo for the first time, after a gap of approximately a century. Our data bighlight the importance of the conservation of the forest fragment and the need for studies on the family in other regions in the State. We provide an illustrated taxonomic key, descriptions, comments on taxonomy, geographic distribution and ecology of the species, in addition to the conservation of their populations in the area.
\end{abstract}

\section{Introdução}

Cactaceae distribui-se quase que exclusivamente no Novo Mundo, sendo Rhipsalis baccifera (J.M. Muell.) Stearn a única espécie a ocorrer no Velho Mundo (Taylor, 1997). A família exibe ampla variedade de formas, hábitos e tamanhos, com espécies discoides e globosas até colunares e arbóreas, ocupando desde desertos até florestas tropicais, de ambientes costeiros a regiões montanhosas de altitude (Cullmann et al., 1986). A principal sinapomorfia da família é a presença de aréolas, ramos altamente especializados com entrenós muito curtos, de onde nascem espinhos, tricomas e flores (Mauseth, 2006).

A família é dividida em cinco subfamílias: Pereskioideae, Opuntioideae, Cactoideae, Maihuenioideae e Leuenbergerioideae (Hunt et al., 2006; Mayta; Molinari-Novoa, 2015), as três primeiras 
ocorrentes no leste do Brasil, o terceiro maior centro de diversidade e endemismo de Cactaceae (Taylor, 1997). Parte da região é ocupada pela Floresta Atlântica brasileira (Taylor; Zappi, 2004), um dos 34 botspots mundiais de biodiversidade, que conta atualmente com apenas 13,1\% da sua área natural remanescente (Conservação Internacional, 2005; SOS Mata Atlântica; INPE, 2019). Metade das espécies de angiospermas da Floresta Atlântica são endêmicas do domínio, incluindo 58 cactáceas, e sua fragmentação culmina na perda da qualidade do hábitat, isolando e colocando em risco as populações de espécies do domínio Atlântico (BFG, 2015; Zappi et al., 2011).

O estado do Espírito Santo encontra-se totalmente inserido na Floresta Atlântica, e nele, são registradas 38 espécies nativas de cactos, subordinadas a 13 gêneros, que representam 13,2\% e 31,7\% das espécies e gêneros brasileiros, respectivamente (Zappi; Taylor, 2020; Cardoso et al., 2018). Contudo, grande parte do território do estado apresenta baixa densidade de coletas de cactáceas (Cardoso et al., 2018), e os registros de ocorrência da família estão concentrados em coletas realizadas para estudos florísticos e fitossociológicos, muitos deles com restrição à fitofisionomia e ao hábito das plantas amostradas (e.g., Pereira et al., 1992; Pereira; Araújo, 1995; Fabris; Cesar, 1996; Pereira; Assis, 2000; Assis et al., 2004; Colodete; Pereira, 2007; Leite et al., 2007; Santos et al., 2010; Saiter et al., 2011; Monteiro et al., 2014). Trabalhos florísticos-taxonômicos acerca de Cactaceae no território do Espírito Santo são escassos, concentrados principalmente em estudos de escala geográfica ampla, que abordam brevemente seu território (e.g., Zappi, 1994; Taylor; Zappi, 2004; Calvente, 2010).

$\mathrm{Na}$ Região Metropolitana de Vitória estão presentes fragmentos florestais rodeados pela malha urbana, que concentram riqueza ainda desconhecida, mas cuja presença de elementos de Cactaceae se mostram conspícuos. Aqui, nós avaliamos a riqueza de Cactaceae em um fragmento de Floresta Atlântica localizado na zona urbana de Vila Velha, no estado do Espírito Santo, apresentando chave taxonômica ilustrada, descrições e comentários sobre a taxonomia e distribuição das espécies. Discussões ainda pouco exploradas sobre a ecologia das espécies e declínio de sua população local também são apresentados.

\section{Material e Métodos}

O Morro do Moreno é uma área declarada como bem natural de interesse à preservação pelo Artigo 314 da Lei complementar n. ${ }^{\circ} 65$ (Vila Velha, 2018), representando um fragmento de Floresta Atlântica localizado em área urbana do município de Vila Velha, Região Metropolitana de Vitória, Espírito Santo, sob as coordenadas 20¹9'38"S-40¹6'41"W, $20^{\circ} 19^{\prime} 24^{\prime \prime S}-40^{\circ} 16^{\prime} 25^{\prime \prime W}$ (Figura 1). Segundo a classificação de Köppen, o clima da região é do tipo Am, tropical de monção (Alvares et al. 2013), com pluviosidade anual de $1.318 \mathrm{~mm}$ (INMET, 2020). A topografia da região é bastante uniforme, com acidentes ao longo das praias, de onde afloram rochas do complexo granito-gnáissico (Ruschi, 1950). A área é constituída por vegetação em diferentes graus de regeneração, incluindo macega, floresta em estágio inicial, médio e avançado de regeneração (Brasil, 1994), vegetação de afloramento rochoso (Porembski, 2007), área de plantio de eucalipto e de espécies frutíferas. Fornece serviços ecossistêmicos culturais, que incluem a prática de esportes, beleza cênica e de conservação da paisagem (veja BPBES, 2019). No entanto, seu valor científico ainda não foi documentado.
Figura 1. Localização do Morro do Moreno, município de Vila Velha, Região Metropolitana de Vitória, Espírito Santo, Brasil.

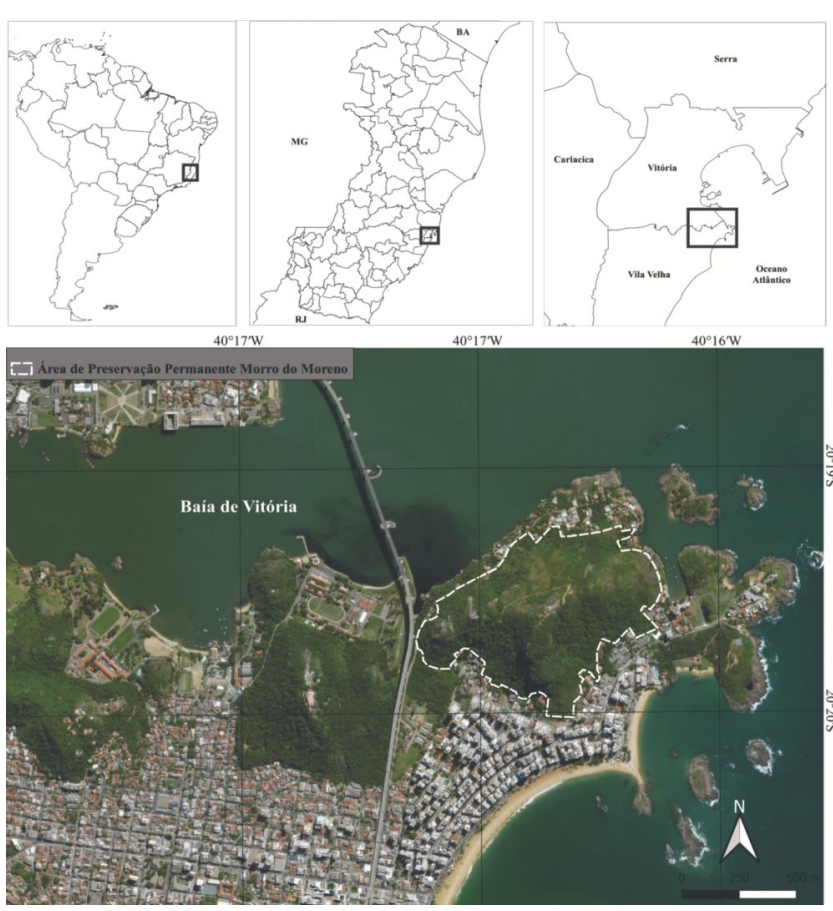

Foram realizadas excursões quinzenais no período entre agosto de 2011 e julho de 2012, com coletas adicionais posteriores, a fim de obter material fértil de representantes de Cactaceae presentes na área de estudo e informações sobre suas fenofases reprodutivas. As buscas pelos espécimes foram realizadas com auxílio de binóculos, e os materiais coletados foram georreferenciados com GPS Garmin76CSx. Flores e frutos foram armazenados em álcool 70\%.

O material foi herborizado segundo Groot (2011) e depositados no Herbário VIES, da Universidade Federal do Espírito Santo. As identificações foram realizadas mediante literatura especializada (Barthlott; Taylor, 1995; Taylor; Zappi, 2004; Calvente, 2010). A classificação das tribos da família seguiu Hunt et al. (2006) e o estado de conservação seguiu IUCN (2019), CNCFlora (2019) e Fraga et al. (2019), para a avaliação no cenário global, nacional e estadual, respectivamente. As descrições foram realizadas a partir de observações do material coletado, com medidas realizadas através de paquímetro analógico. As descrições foram realizadas a partir de observações do material coletado, utilizando-se Taylor e Zappi (2004) para a terminologia específica de Cactaceae e Radford et al. (1974) para o formato das estruturas.

\section{Resultados}

Foram encontradas nove espécies nativas de Cactaceae no Morro do Moreno, pertencentes a sete gêneros, correspondendo a 23,7\% e 53,8\% das espécies e gêneros nativos citados para o Espírito Santo, respectivamente (Cardoso et al., 2018). Rhipsalis russellii Britton \& Rose e R. oblonga Loefgr. são citadas como ameaçadas de extinção (Tabela 1), enquanto Coleocephalocereus fluminensis (Miq.) Backeb., Pilosocereus brasiliensis (Britton \& Rose) Backeb. e R. oblonga são endêmicas da Floresta Atlântica brasileira. 
Cactaceae Juss.

Árvores, arbustos, subarbustos, lianas ou ervas, rupícolas, terrestres ou epífitas. Caule suculento (exceto Pereskia Mill.), costelado, cilíndrico, achatado ou alado, dotado de espinhos e geralmente áfilos - exceto Pereskia e Brasiliopuntia A. Berger. Flores sésseis pediceladas em Pereskia -, actinomorfas, tubo conspícuo ou não; estames numerosos, anteras rimosas, basifixas; ovário ínfero, gamocarpelar, unilocular, pluriovulado, placentação parietal. Frutos lisos ou dotados de aréolas espinescentes, escamas e/ou tubérculos, deiscentes ou indeiscentes, com remanescentes florais decíduos ou persistentes. Sementes reniformes ou discoides, nuas ou envolvidas por envelope funicular.

Chave para identificação das espécies de Cactaceae no Morro do Moreno, ES

1. Caule não suculento. Espinhos pareados na base das folhas. Folhas presentes, 47-84 mm compr. Flores pediceladas (Figura 2a-

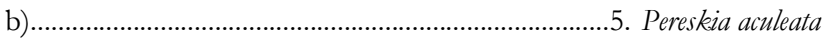

Caule suculento. Espinhos ausentes ou não pareados. Folhas ausentes, se presentes, até $10 \mathrm{~mm}$ compr. Flores sésseis....................2

2. Caule diferenciado em três regiões, tronco cilíndrico, ramos laterais cilíndricos a achatados e ramos terminais achatados. Folhas cônicas, decíduas. Pericarpelo pouco diferenciado dos ramos caulinares jovens (Figura 2c).................................1. Brasiliopuntia brasiliensis

Caule não diferenciado em regiões, costelado, angulado, cilíndrico ou alado. Áfilo. Pericarpelo claramente diferenciado dos segmentos caulinares.

3. Epífita, pendente a semiereta. Flores 0,5-1,05 cm compr.; tubo floral inconspícuo.

Terrícola ou rupícola, cespitosa, decumbente, ereta, prostrada ou escandente. Flores 3,3-28 cm compr.; tubo floral conspícuo......6

4. Caule cilíndrico, segmentos caulinares não costelados. Aréolas imersas no caule, expostas somente após a queda dos frutos. Pericarpelo imerso no caule (Figura 2d)...................7. Rhipsalis floccosa

Caule alado, segmentos caulinares com margem crenada. Aréolas emersas no caule. Pericarpelo emerso no caule.............................5

5. Flores 1,3-1,4 cm diâm. Fruto brancoamarelado ........................................... . .8. Rhipsalis oblonga (Figura 2e)

Flores 0,5-0,7 cm diâm. Fruto magenta .......................................................... . Rhipsalis russellii (Figura 2f

6. Planta prostrada ou escandente. Caule 3-angulado. Espinhos caulinares cônicos. Pericarpelo densamente coberto por aréolas com finos espinhos (Figura 2g)........................... Hylocereus setaceus

Planta cespitosa, decumbente ou ereta. Caule 4-19-costelas. Espinhos caulinares aciculares. Pericarpelo sem aréolas......................7

7. Caule 8-19-costelas. Cefálio lateral nos indivíduos maduros, composto por tricomas lanosos brancos densamente agrupados e intercalados por espinhos amarelados. Frutos deiscentes por poro basal (Figura 2i-j) )................................... Coleocephalocereus fluminensis

Caule 4-5-costelas. Cefálio lateral ausente. Frutos deiscentes por fenda lateral................................................................................... 8

8. Aréolas distando 18-28 $\mathrm{mm}$ entre si, espinhos radiais até 35 $\mathrm{mm}$ compr. Flores 19-23 cm compr. Frutos elipsoides, remanescentes florais decíduos (Figura $2 \mathrm{~h}$ )...
Aréolas distando $8-13 \mathrm{~mm}$ entre si, espinhos radiais até 10 $\mathrm{mm}$ compr. Flores 5,4-6,2 cm compr. Frutos globoso-depressos, remanescentes florais persistentes (Figura 2k1) …................................................................. Pilosocereus brasiliensis

Brasiliopuntia brasiliensis (Willd.) A. Berger, Entwickl. Kakteen 1926;17, 18, 94. (Figuras 2c, 3a)

Árvore ereta, rupícola ou terrestre, até $5 \mathrm{~m}$ alt. Caule suculento, diferenciado em três regiões; tronco c. $6 \mathrm{~cm}$ diâm., cilíndrico; segmentos caulinares intermediários dos ramos laterais cilíndricos a achatados, mais ou menos horizontais, epiderme verde escura a verde amarelada quando exposta ao sol; ramos terminais rômbicos a obovados, achatados, margem irregular, estreitos na base. Aréolas do tronco c. $8 \mathrm{~mm}$ diâm., distando c. $7 \mathrm{~cm}$ entre si, c. 20 espinhos apresentando crescimento secundário, aciculares, os centrais até $40 \mathrm{~mm}$ compr., os radiais até $30 \mathrm{~mm}$ compr.; aréolas dos ramos laterais c. $1 \mathrm{~mm}$ diâm., distando 11-28 mm entre si, portando tricomas lanosos e gloquídeos, podendo apresentar ou não espinho, 11$25 \mathrm{~mm}$ compr.; cefálio lateral ausente. Folhas 2-10 × 1-3 mm, decíduas, cônicas, suculentas, verdes. Flores $28-30 \times 30 \mathrm{~mm}$, sésseis; tubo floral inconspícuo; segmentos externos do perianto até $10 \times 7 \mathrm{~mm}$, trulados, verde-amarelados, suculentos; segmentos internos do perianto até $16 \times 7 \mathrm{~mm}$, lanceolados a espatulados, amarelos, levemente suculentos; estames c. 0,6 cm, livres, anteras c. $1 \times 0,5 \mathrm{~mm}$; pericarpelo verde, $13-18 \times 10-12 \mathrm{~mm}$, pouco diferenciado dos ramos caulinares jovens, aréolas elevadas por podários, gloquídeos, tricomas e folhas presentes; estilete $9-13 \times 1-3 \mathrm{~mm}$, estigma 5-ramificado, 2,5-3,5 × 0,8 mm. Frutos 2-2,8 × 2-2,7 $\mathrm{mm}$, globosos, indeiscentes, remanescentes florais decíduos; pericarpo amarelado, levemente tuberculado, sem escamas, portando aréolas dotadas de grande quantidade de gloquídeos marrons; polpa funicular fibrosa, amarelada. Sementes 6,4-7,1 × 5,3-6 mm, c. 4, reniformes, envolvidas por envelope funicular castanho, fosco.

Material examinado - BRASIL, Espírito Santo: Vila Velha, Morro do Moreno, 8/IX/2011, fr., Cardoso 26 (VIES); loc. cit., 2/ X/2011, fr., Cardoso 125 (VIES); loc. cit., 6/XI/2011, fl., Cardoso \& Santos 37 (VIES); loc. cit., 8/IV/2012, fr., W.C. Cardoso 136 (VIES); loc. cit., 30/VI/2013, fr., Cardoso \& Sarnaglia Junior 275 (VIES); loc. cit., 25/I/2014, fr., Cardoso \& Dal col 303 (VIES).

Material adicional - BRASIL, Espírito Santo: Vitória, Campus de Goiabeiras da Universidade Federal do Espírito Santo, 14/ XI/2011, fl., Cardoso \& Barros 43 (VIES).

Amplamente distribuída na América do Sul, ocorre em todas as regiões do Brasil, além de Paraguai, leste da Bolívia, Peru e norte da Argentina (Anderson, 2001; Zappi; Taylor, 2020). No Morro do Moreno ocorre nas escarpas mais íngremes, formando comunidade com Pilosocereus brasiliensis, Hylocereus setaceus, Ceiba erianthos (Cav.) K.Schum., Anthurium cleistanthum G.M. Barroso, Lippia origanoides Kunth., Paliavana prasinata (Ker Gawl.) Benth., Senegalia lacerans (Benth.) Seigler \& Ebinger., Cnidosculus sp., Pseudobombax sp., Canna indica L., Commelina sp., Ipomoea sp. e Talinum paniculatum (Jacq.) Gaertn. A espécie também é encontrada no interior de mata, sobre matacões rochosos ou desenvolvendo-se em solo raso acumulado em fissuras. 
Figura 2. Cactáceas encontradas no Morro do Moreno, Vila Velha, ES. Pereskia aculeata: A. Ramo com folhas persistentes e fruto; B. Espinhos pareados no caule (Cardoso \& Hirata 270). Brasiliopuntia brasiliensis: C. Artículos, pericarpelo e botão floral (Cardoso \& Santos 37). Rhipsalis floccosa: D. Flor com pericarpelo imerso no caule cilíndrico (Cardoso \& Valadares 2). Rhipsalis oblonga: E. Ramo alado (Cardoso \& Thomaz 152). Rhipsalis russellii: F. Ramo alado (Cardoso \& Valadares 13). Hylocereus setaceus: G. Flor com pericarpelo coberto por podários e espinhos (Cardoso \& Santos $41 \mathrm{~b}$ ). Cereus fernambucensis: H. Flor com pericarpelo coberto por escamas bracteais (Cardoso \& Valadares 12). Coleocephalocereus fluminensis: I. Caule costelado; J. Detalhe do cefálio lateral com remanescentes florais e fruto (Cardoso 25). Pilosocereus brasiliensis: K. Caule costelado; L. Fruto globoso-depresso com remanescentes florais persistentes (Cardoso \& Valadares 4). Ilustradas por Reinaldo A. Pinto.
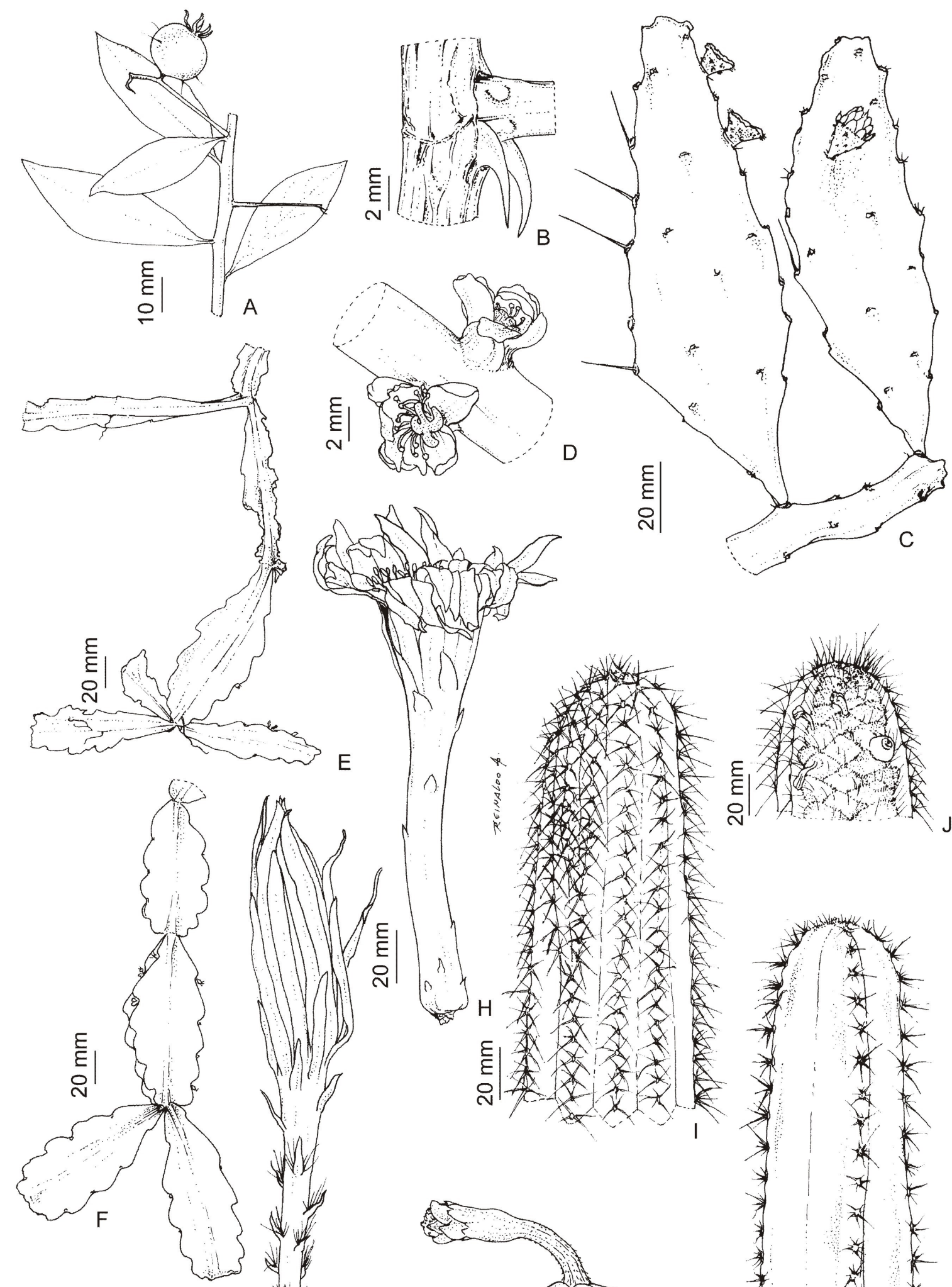

列

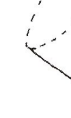


$\mathrm{Na}$ área, é facilmente diferenciada das outras espécies por ser a única a chegar ao porte arbóreo, por possuir ramos achatados e aréolas com gloquídeos. Foi observada florescendo nos meses de setembro e novembro, e frutificando de janeiro a outubro. O declínio da população dessa espécie na área foi constatado durante a implantação de torres de tirolesa sobre afloramento rochoso.

Cereus fernambucensis Lem., Cact. gen. nov. sp. 1839;58. (Figuras 2h, 3b).

Subarbusto cespitoso, rupícola, até 1,3 m alt. Caule c. 9,5 cm diâm., costelado, suculento, ramificado basalmente, 4-5 costelas, c. $4 \times 15$ $\mathrm{mm}$, constrições ao longo do caule; epiderme verde-pálida, verdeazulada a verde-amarelada. Aréolas até $6 \mathrm{~mm}$ diâm., distando 18-28 $\mathrm{mm}$ entre si, portando tricomas lanosos acinzentados e espinhos aciculares, amarelos a amarronzados, 8-10 por aréola, diferenciados em centrais e radiais, os radiais até $35 \mathrm{~mm}$ compr. e os centrais até $62 \mathrm{~mm}$ compr; cefálio lateral ausente. Flores $19-23 \times 11-13 \mathrm{~cm}$, sésseis; tubo floral conspícuo, c. $10 \mathrm{~cm}$ compr., verde-amarelado, escamas bracteais até $13 \times 7 \mathrm{~mm}$; segmentos externos do perianto 50-68 $\times 12 \mathrm{~mm}$, lanceolados, verde amarelado, levemente suculentos; segmentos internos do perianto c. $70 \times 10 \mathrm{~mm}$, lanceolados, brancos, delicados; estames c. $18 \mathrm{~cm}$ compr., epipétalos, anteras c. 3 $\times 1,7 \mathrm{~mm}$; pericarpelo verde-amarelado, c. $15 \times 11 \mathrm{~mm}$, claramente diferenciado dos segmentos caulinares, dotado de pequenas escamas bracteais, triangulares, c. $2 \times 2 \mathrm{~mm}$, esparsas, aréolas e tubérculos ausentes; estilete 11-14 × $2 \mathrm{~mm}$, estigma 12-ramificado, 13-14 $\times 1$ $\mathrm{mm}$. Frutos c. $52 \times 40 \mathrm{~mm}$ elipsoides, deiscentes por fenda lateral, remanescentes florais decíduos; pericarpo magenta, verde quando imaturo, liso; polpa funicular branca. Sementes c. $2,2 \times 1,6 \mathrm{~mm}$, numerosas, reniformes, nuas, pretas, brilhantes.

Material examinado - BRASIL, Espírito Santo: Vila Velha, Morro do Moreno, 21/VIII/2011, fl., Cardoso \& Valadares 12 (VIES); loc. cit., 17/XII/2011, fr., Cardoso, Borges \& Santos 46 (VIES); loc. cit., 16/VI/2013, fr., Cardoso \& Hirata 271 (VIES).

Material adicional - BRASIL, Espírito Santo: Vila Velha, Parque Estadual Paulo César Vinha, 7/IV/2013, fl. e fr., Cardoso \& Borges 269 (VIES). Vitória, Campus de Goiabeiras da Universidade Federal do Espírito Santo, 3/III/2012, fl., Cardoso $87 b$ (VIES).

Cereus fernambucensis é endêmica do Brasil, ocorrendo desde o Ceará até São Paulo (Zappi; Taylor, 2020). No Morro do Moreno, foi encontrada formando pequenos agrupamentos em afloramentos rochosos. A espécie sofre redução populacional por meio de pisoteio proporcionado pelo turismo predatório e pelo pastoreio de equinos. Somado a isso, queimadas descaracterizam o hábitat da espécie, facilitando a substituição por espécies exóticas (e.g., Furcraea foetida (L.) Haw.).

Diferencia-se das outras espécies da área pelo hábito subarbustivo associado às flores com tubo longo. Diferentemente de $H$. setaceus, possui caules não trepadores, 4-5 costados, espinhos caulinares aciculares e pericarpelo coberto apenas por pequenas escamas bracteais. Foi observada florescendo em março e agosto, e frutificando em junho e dezembro.

Coleocephalocereus fluminensis (Miq.) Backeb., Deutsch. Kakteen Ges. 1941;(2):53. (Figuras 2i-j, 3c).

Erva decumbente, rupícola, até $2 \mathrm{~m}$ compr., formando touceiras, parte ereta com até $70 \mathrm{~cm}$ alt. Caule $56-82 \mathrm{~mm}$ diâm., costelado, suculento, ramificado basalmente, 8-19 costelas, 7-9 × 9-12 mm, rasas, epiderme verde-clara, acinzentada nas porções basais mais antigas. Aréolas 1-4 $\mathrm{mm}$ diâm., distando 6-9 mm entre si, tricomas lanosos brancos a acinzentados na região apical dos ramos, espinhos aciculares, amarelos a acinzentados, 6-9 por aréola, até 27 mm compr., os centrais e radiais diferenciados somente no tamanho, os radiais medindo até $2 / 3$ dos espinhos centrais; cefálio lateral 2-8 cm diâm., presente nos indivíduos maduros, composto por tricomas lanosos brancos densamente agrupados e intercalados por espinhos amarelados, iniciando-se no ápice do caule e podendo estender-se até a base da região ereta. Flores 3,3-3,9 × 1,3-1,9 cm, sésseis; tubo floral conspícuo, 2,7-3,2 × 0,7-1,3 cm, creme, escamas bracteais esparsamente presentes em sua parte superior; segmentos externos do perianto c. $8 \times 3-4 \mathrm{~mm}$, lanceolados, marrons apicalmente; segmentos internos c. $11 \times 8 \mathrm{~mm}$, ovados, brancos; estames c. $28 \mathrm{~mm}$, epipétalos, anteras c. 1,6 $\times 0,7 \mathrm{~mm}$; pericarpelo creme, c. $4 \times 5-6, \mathrm{~mm}$, claramente diferenciado dos segmentos caulinares, escamas, aréolas e podários ausentes; estilete $28 \times 1$ $\mathrm{mm}$, estigma c. 11-ramificado, c. $5 \times 0,7 \mathrm{~mm}$. Frutos 15-18 × 10$14 \mathrm{~mm}$, obovoides a amplamente obovoides, deiscentes por poro basal, remanescentes florais persistentes; pericarpo magenta, liso; polpa funicular gelatinosa. Sementes c. $1,2 \times 1 \mathrm{~mm}$, numerosas, reniformes, nuas, pretas, brilhantes.

Material examinado - BRASIL, Espírito Santo: Vila Velha, Morro do Moreno, 7/VIII/2011, fl., Cardoso \& V Valadares 3 (VIES); loc. cit., 8/IX/2011, fl. e fr., Cardoso 25 (VIES).

Material adicional - BRASIL, Espírito Santo: Vitória, Campus de Goiabeiras da Universidade Federal do Espírito Santo, 8/ VIII/2011, fl., Cardoso 6 (VIES); Morro da Gamela, 15/VIII/2011, fl., Cardoso, Tavares \& Barros 8 (VIES).

Coleocephalocereus fluminensis é endêmica da Floresta Atlântica da região Sudeste do Brasil (Zappi; Taylor, 2020). No Morro do Moreno foi encontrada amplamente distribuída nos afloramentos rochosos, formando comunidade com Cyperus hermaphroditus (Jacq.) Standl., Alcantarea sp., Croton glandulosus L., Portulaca giuliettiae T.Vieira \& A.A. Coelho, Cololobus rupestris (Gardner) H. Rob., Lippia origanoides, Hylocereus setaceus, Pilosocereus brasiliensis, Pereskia aculeata, Sinningia brasiliensis (Regel \& Schmidt) Wiehler \& Chautems, Billbergia amoena (Lodd.) Lindl., Erythrina falcata Benth., Cyrtopodium sp. e Commelina sp.

É exclusivamente rupícola e destaca-se pelo caule longo, decumbente e com mais de oito costelas. É a única espécie da área a apresentar cefálio lateral, região do ramo originada do meristema apical caulinar, não fotossintética e especializada na produção de flores, composta por aréolas densamente agrupadas que produzem também grande quantidade de espinhos e tricomas (Gorelick, 2016). Apesar das flores no gênero serem originadas exclusivamente dos cefálios, elas são produzidas por distintas aréolas, não sendo tratadas como inflorescências.

Foi observada florescendo e frutificando entre junho e setembro. Apesar de ser uma espécie comum na área, o declínio de agrupamentos foi observado com a impla0ntação de mirante, turismo desordenado e pisoteio de equinos.

Hylocereus setaceus (Salm-Dyck) R.Bauer, Cactaceae Syst. Initiatives. 2003;17:29. (Figuras 2g, 3d)

Erva prostrada ou escandente, geralmente rupícola, formando touceiras. Caule $2-5 \mathrm{~cm}$ diâm., suculento, ramificado lateralmente, 3-angulado, suculento, constrito na base dos segmentos caulinares; 
Figura 2. Cactos do Morro do Moreno. Brasiliopuntia brasiliensis em frutificação (a); Cereus fernambucensis com fruto passado (b); Coleocephalocereus fluminensis com sua flor produzida no cefálio lateral (c); população de Hylocereus setaceus em afloramento rochoso (d); ramo de Pereskia aculeata em frutificação (e) e Pilosocereus brasiliensis em floração (f); espécime de Rhipsalis floccosa a pleno sol (g): frutos maduros de Rhipsalis oblonga (h) e Rhipsalis russellii (i).
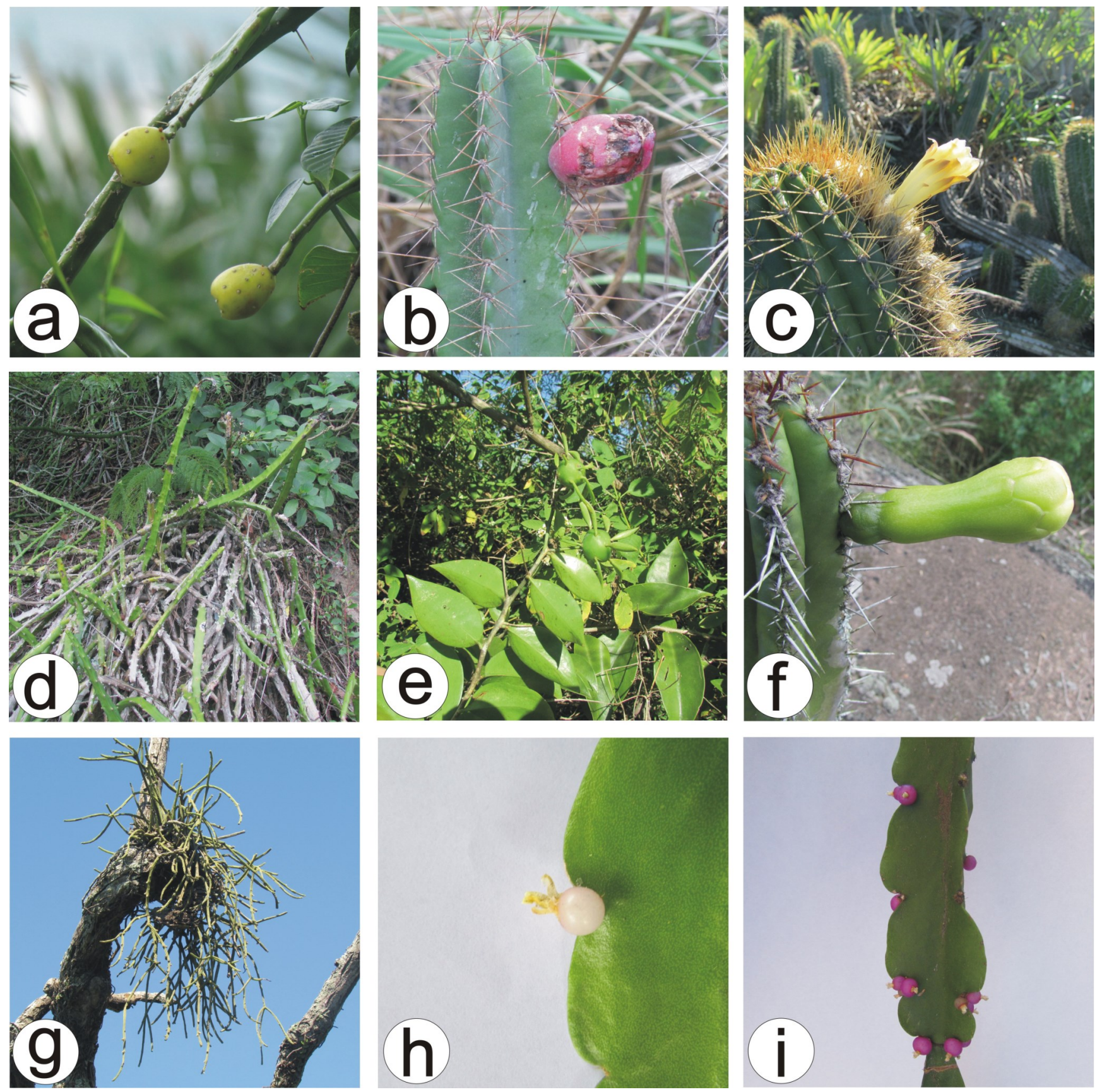

Tabela 1. Espécies de Cactaceae encontradas no Morro do Moreno, município de Vila Velha, ES. Estado de conservação, segundo (1) IUCN (2019), CNCFlora (2019) ou (2) Fraga et al. (2019) - LC: pouco preocupante; NT: quase ameaçada; VU: vulnerável; EN: em perigo; NE: não avaliada. Endemismos - BRA: espécie endêmica do Brasil; FAT: endêmica da Floresta Atlântica.

\begin{tabular}{|c|c|c|c|}
\hline Subfamília & Espécie & Conservação & Endemismo \\
\hline Cactoideae & Cereus fernambucensis Lem. & $\mathrm{LC}^{1,3}$ & BRA \\
\hline Cactoideae & Coleocephalocereus fluminensis (Miq.) Backeb. & $\mathrm{LC}^{1} ; \mathrm{NT}^{3}$ & BRA, FAT \\
\hline Cactoideae & Pilosocereus brasiliensis (Britton\& Rose) Backeb. & $\mathrm{LC}^{1} ; \mathrm{NT}^{2,3}$ & BRA, FAT \\
\hline Cactoideae & Hylocereus setaceus (Salm-Dyck) R.Bauer & $\mathrm{LC}^{1,2,3}$ & - \\
\hline Cactoideae & Rhipsalis floccosa Salm-Dyck ex Pfeiff. & $\mathrm{LC}^{1,2,3}$ & - \\
\hline Cactoideae & Rhipsalis oblonga Loefgr. & $\mathrm{VU}^{1} ; \mathrm{NT}^{2} ; \mathrm{NE}^{3}$ & BRA, FAT \\
\hline Cactoideae & Rbipsalis russellii Britton \& Rose & $\mathrm{LC}^{2} ; \mathrm{VU}^{1} ; \mathrm{EN}^{3}$ & BRA \\
\hline Opuntioideae & Brasiliopuntia brasiliensis (Willd.) A.Berger & $\mathrm{LC}^{1,2,3}$ & - \\
\hline Pereskioideae & Pereskia aculeata Mill. & $\mathrm{LC}^{1,2,3}$ & - \\
\hline
\end{tabular}


margem ondulada; epiderme verde, amarelada quando exposta ao sol. Aréolas 3-6 mm diâm., distando 20-40 mm entre si, produzindo tricomas brancos e 2-6 espinhos por aréola, cinzas a amarronzados, 2-6 × 1-2 mm, cônicos, curvados; cefálio lateral ausente. Flores 25-28 cm comp., sésseis; tubo floral conspícuo, 10-12 $\times 1$ $2,5 \mathrm{~cm}$, escamas bracteais $10-47 \times 2-6 \mathrm{~mm}$, aréola espinescente em sua axila; segmentos externos do perianto até $10 \mathrm{~cm}$ comp., lanceolados a lineares, verdes, vinosos no ápice, suculentos; segmentos internos do perianto até $3 \mathrm{~cm}$ larg., lanceolados, brancos, delicados; estames 19-22 cm, epipétalos, anteras 4-5 × 1-2 mm; pericarpelo esverdeado, c. $26 \times 20 \mathrm{~mm}$, claramente diferenciado dos segmentos caulinares, densamente coberto por aréolas elevadas por podários, portando 9-15 finos espinhos; estilete 19-21 × 1,4 cm, estigma c. 18-ramificado, $10-20 \times 0,5 \mathrm{~mm}$. Frutos $61 \times 45 \mathrm{~mm}$, ovoides, indeiscentes ou rompendo-se irregularmente, remanescentes florais decíduos; pericarpo vermelho, apresentando tubérculos 1-15 ×9$14 \mathrm{~mm}$, cobertos por espinhos decíduos, estes até $15 \mathrm{~mm}$ comp.; polpa funicular branca. Sementes c. $4 \times 2,5 \mathrm{~mm}$, numerosas, reniformes, nuas, pretas, brilhantes.

Material examinado - BRASIL, Espírito Santo: Vila Velha, Morro do Moreno, 17/XII/2011, fr., Cardoso, Borges \& Santos 47 (VIES); loc. cit., 6/XI/2011, fl., Cardoso \& Santos $41 b$ (VIES); loc. cit., 21/VIII/2011, bot., Cardoso \& Valadares 10 (VIES); loc. cit., 2/ X/2011, fl., Cardoso 124 (VIES).

Material adicional - BRASIL, Espírito Santo: Vitória, Campus de Goiabeiras da Universidade Federal do Espírito Santo, 17/ XI/2011, fr., Cardoso \& Pesente 45 (VIES).

Ocorre na Bolívia, Paraguai, Argentina e Brasil, e neste, distribuise amplamente, ocorrendo em todas as regiões do país (Anderson, 2001; Zappi; Taylor, 2020). No Morro do Moreno, foi encontrada em afloramentos com alta declividade, sobre matacões rochosos na macega e no estágio inicial de regeneração e em ecótono com floresta de grota. A espécie forma comunidade com Pilosocereus brasiliensis, Brasiliopuntia brasiliensis, Ceiba erianthos, Anthurium cleistanthum, Lippia origanoides, Paliavana prasinata, Senegalia lacerans, Cnidosculus sp., Pseudobombax sp., Canna indica, Commelina sp., Ipomoea sp. e Talinum paniculatum. Dentre as cactáceas da área, H. setaceus é a única a possuir espinhos cônicos. Diferencia-se de C.fernambucensis pelo caule 3-angulado e pela presença de aréolas espinescentes elevadas por podários no pericarpelo. Foi observada florescendo entre setembro e novembro, e frutificando em novembro e dezembro. Foi observado um declínio populacional da espécie na área, causado por queimadas periódicas que atingem matacões rochosos onde seus indivíduos ocorrem. Conhecida popularmente como saborosa.

Pereskia aculeata Mill., Gard. Dict., ed. 8; Haw. Syn. Pl. Succ. 1768;198. (Figuras 2a-b, 3e).

Liana escandente, rupícola ou terrestre. Caule 3-5 mm diâm., cilíndrico, não suculento, sem constrições; epiderme verde. Aréolas c. $9 \mathrm{~mm}$ diâm., distando $12-70 \mathrm{~mm}$ entre si, portando espinhos uncinados, pareados na base das folhas, $4 \times 4 \mathrm{~mm}$; cefálio lateral ausente. Folhas 47-84 × 18-39 mm, alternas, elípticas, semissuculentas, lâmina foliar verde, concolor, cerosa, peninérvea, base cuneada; pecíolos c. $5 \mathrm{~mm}$ compr. Inflorescência racemosa. Flores 20 $-30 \times 20-35 \mathrm{~mm}$, pediceladas, pedicelos $12-31 \mathrm{~mm}$ compr.; tubo floral inconspícuo; perianto c. 12 segmentos, 7-24 × 5-9 mm, elípticos, brancos; estames livres do perianto, anteras c. $0,7 \times 0,5$ $\mathrm{mm}$; pericarpelo claramente diferenciado dos segmentos caulinares, portando aréolas que produzem espinhos e escamas bracteais, elípticas, reflexas, 11-17 $\times$ 3-5 mm, podários ausentes; estilete c. $2 \times$ 0,5 mm, estigma 5-ramificado, c. 1,4 × 0,5 mm. Frutos 11-16 $\times 12$ $18 \mathrm{~mm}$, depresso-globosos, indeiscentes, inicialmente com escamas bracteais e aréolas espinescentes; pericarpo amarelo-alaranjado; polpa funicular gelatinosa. Sementes c. $5 \times 5 \mathrm{~mm}, 1-5(-6)$, discóides, nuas, pretas, brilhantes.

Material examinado - BRASIL, Espírito Santo: Vila Velha, Morro do Moreno, 7/VIII/2011, fr., Cardoso \& V aladares 5 (VIES); loc. cit., 16/VI/2013, fr., Cardoso \& Hirata 270 (VIES).

Material adicional - BRASIL, Espírito Santo: Guarapari, Setiba, 25/IV/1989, fl., Pereira 1959 (VIES). Vila Velha, Ilha das Garças, 07/IV/2012, fl., Barros \& Silva 66 (VIES). Vitória, Campus de Goiabeiras da Universidade Federal do Espírito Santo, 11/VIII/2011, fr., Cardoso et al. 7 (VIES); loc. cit., 9/III/2012, bot., Cardoso \& Firmino 177 (VIES).

É encontrada na Flórida, México, América Central e América do Sul (Anderson, 2001). No Brasil, ocorre desde Pernambuco até o Rio Grande do Sul, e também no Maranhão Ceará e Goiás (Zappi; Taylor, 2020). No Morro do Moreno foi encontrada em afloramentos rochosos e em vegetação sob diferentes estágios de regeneração. A espécie forma comunidade com P. brasiliensis, Billbergia amoena, Paliavana prasinata, Begonia reniformis Dryand., Senegalia lacerans, Anthurium cleistanthum, Ipomoea sp., Aechmea nudicaulis (L.) Griseb., Pyrostegia venusta (Ker Gawl.) Miers, Coleocephalocereus fluminensis, Hylocereus setaceus, Serjania sp., Sinningia brasiliensis, Erythrina falcata, Cyrtopodium sp., Alcantarea sp. e Commelina sp.

Apesar de ocorrer em várias fitofisionomias, a espécie é representada por poucos indivíduos na área de estudo. Somado a isso, queimadas descaracterizam a vegetação de afloramento rochoso, tornando-a susceptível à substituição por espécies exóticas - e.g., Melinis repens (Willd.) Zizka. É facilmente diferenciada das outras cactáceas da área devido à presença de espinhos pareados no caule e folhas conspícuas, além de ser a única espécie a apresentar inflorescências verdadeiras - i.e., cada racemo se origina de uma única gema axilar. Foi observada em frutificação entre junho e agosto. Conhecida popularmente como ora-pro-nobis, suas folhas são utilizadas na culinária (Taylor; Zappi, 2004).

Pilosocereus brasiliensis (Britton \& Rose) Backeb., Die Cact. 1960;4:2423. (Figuras 2k-1, 3f)

Arbusto ereto, rupícola, até $3 \mathrm{~m}$ alt. Caule 5-9 cm diâm., costelado, suculento, ramificado basalmente, $4-5$ costelas, c. $20 \times 30 \mathrm{~mm}$, profundas, constrito apenas na base dos ramos; epiderme verde. Aréolas 4-5 mm diâm., distando $8-13 \mathrm{~mm}$ entre si, produzindo tricomas marrons a acinzentados, maiores na região apical do caule; 7-9 espinhos por aréolas, cinzas a amarronzados, aciculares, diferenciados em centrais e radiais, os radiais até $10 \mathrm{~mm}$ compr., os centrais até $25 \mathrm{~mm}$ compr.; cefálio lateral ausente. Flores 5,4-6,2 $\times$ 1,8-2,1 cm, sésseis; tubo floral conspícuo, 3,5-4,0 cm compr., verde-amarelado, sinuoso, escamas bracteais presentes apicalmente, 5$7 \times 9 \mathrm{~mm}$; segmentos externos do perianto até $12 \mathrm{~mm}$ compr., largamente trulados, esverdeados, semissuculentos; segmentos internos ovados, brancos, delicados; estames c. $45 \mathrm{~mm}$ compr., epipétalos, anteras c. $3 \times 1 \mathrm{~mm}$; pericarpelo verde, c. $10 \times 13 \mathrm{~mm}$, claramente diferenciado dos segmentos caulinares, escamas, aréolas 
e podários ausentes; estilete c. $32 \times 1,6 \mathrm{~mm}$, estigma 8-ramificado, c. $8 \times 0,8 \mathrm{~mm}$. Frutos c. $30 \times 42 \mathrm{~mm}$, globoso-depressos, deiscentes por fenda lateral, remanescentes florais persistentes; pericarpo rugoso, verde, algumas vezes vináceo após deiscência; polpa funicular vinácea. Sementes c. $2 \times 1 \mathrm{~mm}$, numerosas, reniformes, nuas, pretas, brilhantes.

Material examinado - BRASIL, Espírito Santo: Vila Velha, Morro do Moreno, 7/VIII/2011, fl. e fr., Cardoso \& Valadares 4 (VIES); loc. cit., 16/VI/2013, W.C. Cardoso et al. 272 (VIES).

Material adicional - BRASIL, Espírito Santo: Vila Velha, Parque Natural Municipal de Jacarenema, V/1990, O.J. Pereira 2120 (VIES). Vitória, Campus de Goiabeiras da Universidade Federal do Espírito Santo, I/2012, fl., Cardoso 56 (VIES); loc. cit., 6/VIII/2012, fl., Cardoso \& Firmino 175 (VIES).

Pilosocereus brasiliensis é endêmica da Floresta Atlântica brasileira, ocorrendo nos estados da Bahia, Espírito Santo, Minas Gerais e Rio de Janeiro (Zappi; Taylor, 2020). Diferencia-se das outras espécies por seu hábito arbustivo, ereto, portando flores com 5-7 cm e frutos globoso-depressos, com remanescentes florais persistentes.

Neste estudo foi encontrada formando numerosos agrupamentos no topo do morro. Forma comunidade com Brasiliopuntia brasiliensis, Hylocereus setaceus; Ceiba erianthos (Cav.) K.Schum., Anthurium cleistanthum, Lippia origanoides, Paliavana prasinata, Senegalia lacerans, Cnidosculus sp., Pseudobombax sp., Canna indica, Commelina sp., Ipomoea sp. e Talinum paniculatum (Jacq.) Gaertn. O histórico da área aponta a ocorrência de várias queimadas nos últimos 20 anos, tornando a vegetação de afloramento rochoso susceptível à substituição por espécies exóticas (e.g., Melinis repens (Willd.) Zizka). Somado a isso, agrupamentos de P. brasili ensis têm sido reduzidos nos trechos que concentram turismo desordenado. Foi observada em floração e frutificação durante todo o ano, com um pico entre junho e agosto.

Rhipsalis floccosa Salm-Dyck ex Pfeiff, Enum. Diagn. Cact. 1837;134. (Figuras 2d, 3g).

Erva, epífita pendente, c. $2 \mathrm{~m}$ compr. Caule até $5 \mathrm{~mm}$ diâm., cilíndrico, suculento, ramificado apicalmente, segmentos caulinares c. $20 \mathrm{~cm}$ compr., não costelados; epiderme verde escura a acinzentada. Aréolas submersas no caule, expostas somente após a queda dos frutos, distando 10-35 mm entre si, flocosas, produzindo tricomas brancos e flores solitárias, espinhos ausentes, cavidade areolar c. $4 \mathrm{~mm}$ diâm.; cefálio lateral ausente. Flores c. $0,7 \times 0,8 \mathrm{~cm}$., sésseis; tubo floral inconspícuo; segmentos do perianto c. $3,5 \times 3 \mathrm{~mm}$, pouco diferenciados, ovados, brancos; estames c. $4 \mathrm{~mm}$ compr., livres do perianto, anteras c. $0,4 \times 0,5 \mathrm{~mm}$; pericarpelo imerso no caule, c. $3 \times 3 \mathrm{~mm}$, claramente diferenciado dos segmentos caulinares, aréolas, podários, escamas e espinhos ausentes; estilete c. $3 \times 1$ mm, estigma 3-ramificado, c. 1,5 $\times 0,7 \mathrm{~mm}$. Frutos c. $7 \times 7 \mathrm{~mm}$, globosos, indeiscentes, remanescentes florais persistentes; pericarpo branco, translúcido, liso; polpa funicular mucilaginosa. Sementes c. $1,6 \times 0,5 \mathrm{~mm}$, numerosas, reniformes, nuas, pretas, brilhantes.

Material examinado - BRASIL, Espírito Santo: Vila Velha, Morro do Moreno, 7/VIII/2011, fl., Cardoso \& V Valadares 2 (VIES); loc. cit., 21/VIII/2011, fr., Cardoso \& V aladares 11 (VIES).

Material adicional - BRASIL, Espírito Santo: Vitória, Campus de Goiabeiras da Universidade Federal do Espírito Santo, VIII/2011, fl., Cardoso 14 (VIES); loc. cit., 12/V/2012, fl., Cardoso 144 (VIES); loc. cit., 6/II/2012, fl., Cardoso 58 (VIES); loc. cit., 03/
VI/2011, fr., Cardoso 1 (VIES); loc. cit., 6/VIII/2012, fr., Cardoso \& Firmino 174 (VIES).

Rhipsalis floccosa possui ampla distribuição, ocorrendo na Argentina, Bolívia, Brasil, Paraguai e Venezuela (Barthlott; Taylor, 1995). É uma das espécies de Rhipsalis com maior distribuição no leste do Brasil, ocorrendo da Paraíba ao Rio Grande do Sul, além do Mato Grosso e Mato Grosso do Sul (Zappi; Taylor, 2020). Na Região Metropolitana de Vitória, é comumente encontrada pelas ruas dos municípios de Vila Velha e Vitória, crescendo sobre árvores utilizadas no paisagismo urbano. No Morro do Moreno ocorre em fragmentos florestais, sobre forófitos típicos de áreas em regeneração, como Moquiniastrum polymorphum (Less.) G. Sancho, Machaerium birtum (Vell.) Stellfeld e Campomanesia guaviroba (DC.) Kiaersk. Nos trechos mais preservados ocorre sobre Andira fraxinifolia Benth. e Pachystroma longifolium (Nees) I.M. Johnst., compondo o estrato epifítico com Aechmea nudicaulis, Antburium scandens (Aubl.) Engl. e Microgramma sp. Distingue-se das demais espécies do gênero ocorrentes na área pelo hábito epifítico e caule cilíndrico, com o pericarpelo imerso, deixando uma cavidade no caule após a dispersão do fruto. Foi observada em floração e frutificação de maio a agosto.

Rhipsalis oblonga Loefgr., Arch. Jard. Bot. Rio de Janeiro. 1918;2:36. (Figuras 2e, 3h).

Erva, epífita pendente a semiereta, até $2 \mathrm{~m}$ compr. Caule 2-alado, suculento, ramificado apicalmente, segmentos caulinares 73-150 $\times$ 20-56 mm, elípticos a estreitamente elípticos, margem crenada, projeções marginais 2-9 mm larg.; epiderme verde-escura. Aréolas emersas no caule, 1-1,5 mm diâm., distando 14-38 mm entre si, sendo a primeira de cada segmento distante $26-45 \mathrm{~mm}$ da base, produzindo tricomas brancos e escamas aciculares, 1-3 flores por aréola, espinhos ausentes; cefálio lateral ausente. Flores $0,8-1,0 \times$ 1,3-1,4 cm, sésseis; tubo floral inconspícuo; segmentos externos do perianto $0,7-2 \times 1,2-2,7 \mathrm{~mm}$, muito superficialmente triangular a deltado, amarelo-esverdeados, levemente suculentos, segmentos internos 7-8 × 3,5-4,2 mm, elípticos, amarelos; estames c. $6 \times 0,3$ $\mathrm{mm}$ compr., livres do perianto, anteras c. $0,5 \times 0,7 \mathrm{~mm}$; pericarpelo amarelo-esverdeado, emerso no caule, c. $5 \times 4 \mathrm{~mm}$, claramente diferenciado dos segmentos caulinares, escamas, tubérculos, aréolas e espinhos ausentes; estilete c. 4,4 $\times 1 \mathrm{~mm}$, estigma 3-5-ramificado, c. 2,1 $\times 1,2 \mathrm{~mm}$. Frutos c. $7 \times 7 \mathrm{~mm}$, globosos, ápice truncado, indeiscentes, remanescentes florais persistentes; pericarpo brancoamarelado, liso; polpa funicular mucilaginosa. Semente c. $1,7 \times 1$ $\mathrm{mm}, \mathrm{c.}$ 13, reniformes, nuas, pretas, brilhantes.

Material examinado - BRASIL, Espírito Santo: Vila Velha, Morro do Moreno, 14/VI/2012, fl., Cardoso \& Thomaz 152 (VIES); loc. cit., 14/VI/2012, Cardoso \& Thomaz 153 (VIES); loc. cit., 25/ VI/2013, fl., Cardoso \& Borges 273 (VIES).

Rhipsalis oblonga é endêmica da Floresta Atlântica brasileira, ocorrendo do estado da Bahia até São Paulo (Zappi; Taylor, 2020). Taylor e Zappi (2004) apontam a lacuna de ocorrência da espécie no Espírito Santo, que possuía, até o momento, um único registro de Rhipsalis oblonga, realizado na primeira metade do século XX. A deficiência de registros da espécie no estado é provocada tanto pelo alto nível de similaridade morfológica entre as espécies aladas de Rhipsalis (Calvente, 2010), que dificulta sua identificação, quanto pela baixa densidade de coletas da família pelo território do estado (Taylor; Zappi, 2004; Cardoso et al., 2018). No presente estudo, foi encontrada na borda de fragmentos florestais e também em forófi- 
tos que compõem a vegetação mais preservada do Morro do Moreno (e.g., Pachystroma longifolium), situada nos trechos mais côncavos da montanha. Compõe o estrato epifítico juntamente com Aechmea nudicaulis (L.) Griseb., Microgramma sp. e R. floccosa.

Diferencia-se de R. floccosa por possuir ramos alados e pericarpelo emerso no caule, e de R. russellii por apresentar flores maiores que $7 \mathrm{~mm}$ diâmetro, enquanto esta possui flores com diâmetro menor $(5-7 \mathrm{~mm})$. Floresceu entre os meses de abril e julho, e frutificou em julho e agosto.

Rhipsalis russellii Britton \& Rose, Cactaceae. 1923;4:242. (Figuras 2f, 3i).

Erva, epífita pendente a semiereta, até 1,5 m compr. Caule 2-3 alado, suculento, ramificado apicalmente, segmentos caulinares 56$106 \times 24-48 \mathrm{~mm}$, elípticos, margem crenada, projeções marginais 5 $-8 \mathrm{~mm}$; epiderme verde-escura, margem avermelhada quando exposta ao sol. Aréolas emersas no caule, 1,4-2,6 mm diâm., distando 14-28 mm entre si, sendo a primeira do segmento distante 14$17 \mathrm{~mm}$ de sua base, produzindo tricomas brancos e escamas aciculares, 1-3(-várias) flores por aréola, espinhos ausentes; cefálio lateral ausente. Flores $0,5-0,6 \times 0,5-0,7 \mathrm{~cm}$, sésseis; tubo floral inconspícuo; segmentos externos do perianto $0,8-0,9 \times 1,4-1,6 \mathrm{~mm}$, superficialmente triangular, esverdeados, suculentos, segmentos internos verde-amarelados 2,8-3,3 × 1,9-2,4 mm, ovados, amarelos, levemente translúcidos; estames c. $2 \mathrm{~mm}$ compr., livres do perianto, anteras c. $0,3 \times 0,3 \mathrm{~mm}$; pericarpelo verde, emerso no caule, c. $3 \times 3 \mathrm{~mm}$, claramente diferenciado dos segmentos caulinares, escamas, tubérculos, aréolas e espinhos ausentes; estilete c. 1,9 $\times 0,8 \mathrm{~mm}$, estigma 6-ramificado, c. $1 \times 0,4 \mathrm{~mm}$. Frutos $4-6 \times 4-5$ $\mathrm{mm}$, globosos, indeiscentes, remanescentes florais persistentes; pericarpo magenta, verde quando imaturo, liso; polpa funicular mucilaginosa. Sementes c. $1-1,2 \times 0,5-0,7 \mathrm{~mm}$, numerosas, reniformes, nuas, pretas, brilhantes.

Material examinado - BRASIL, Espírito Santo: Vila Velha, Morro do Moreno, 21/VIII/2011, fr., Cardoso \& Valadares 13 (VIES); loc. cit., 17/VIII/2013, fl. e fr., Cardoso \& Sarnaglia Junior 277 (VIES).

Espécie endêmica do Brasil, distribuindo-se nos estados da Bahia, Espírito Santo, Goiás, Mato Grosso, Minas Gerais, Paraná e Rio de Janeiro (Zappi Taylor, 2020). No Morro do Moreno, foi encontrada na borda de fragmentos florestais. Pode ser encontrada associada a forófitos como Moquiniastrum polymorphum e Campomanesia guaviroba, compondo o estrato epífitico com Aechmea nudicaulis, Anthurium scandens, Microgramma sp. e R. floccosa.

Diferencia-se de R. floccosa por possuir ramos alados e pericarpelo emerso no caule, e de R. oblonga pela capacidade de produção de mais de quatro flores por aréola, além da coloração magenta de seus frutos. Apesar de algumas espécies de Rhipsalis serem capazes de apresentar flores agrupadas em uma mesma aréola, esses órgãos são produzidos por gemas axilares originadas em diferentes nós do ramo curto. Dessa forma, esse arranjo de flores não é classificado como inflorescência. Rhipsalis russellii floresceu nos meses de junho e julho, e frutificou de julho a setembro.

\section{Discussão}

Apresentamos pela primeira vez um estudo taxonômico de Cactaceae para o Espírito Santo, onde encontramos nove espécies de Cactaceae em uma área com relevante interesse para preservação regional, inserida em matriz urbana. Contribuímos assim para a expansão do conhecimento da família no estado, em particular na Região Metropolitana de Vitória.

Estudos florísticos sobre Cactaceae em regiões metropolitanas têm apontado riqueza considerável mesmo quando acompanhado por impactos relevantes, como em Calvente et al. (2005), Calvente e Andreata (2007) e Vasconcelos et al. (2019). Nosso estudo investigou um remanescente de menor tamanho, e poderá servir como modelo para comparação entre remanescentes de dimensões semelhantes (e.g. Verçoza; Bastos, 2013).

Dois pontos chaves podem ser discutidos sobre nossos dados. $\mathrm{O}$ primeiro deles trata da capacidade que algumas Cactaceae possuem em colonizar florestas em regeneração (Bonnel et al., 2009; Ceballos, 2020), observado na área de estudo nos trechos com histórico de uso e atualmente recoberto por espécies pioneiras, como Moquiniastrum polymorphum, Machaerium birtum e Campomanesia guaviroba. Apesar de Taylor e Zappi (2004) sugerirem uma possível relação sobre o sucesso de colonização das Rhipsalideae em árvores com fustes largos e idade longeva, nossas observações indicam que, localmente, espécies de Rhipsalis também ocorrem de maneira expressiva sobre espécies arbóreas secundárias iniciais. Essas observações são importantes porque podem auxiliar estudos de licenciamento ambiental que exigem indicadores (e.g., riqueza de epífitas) para caracterização de estágios sucessionais (Brasil, 1994). Das espécies arbóreas relacionadas, C. guaviroba é o único elemento não relacionado em estudos regionais de regeneração no mesmo tipo vegetacional (e.g., Saiter et al., 2011), apesar de estudos citarem sua ocorrência em áreas perturbadas no Espírito Santo (Luber et al., 2017).

O segundo ponto diz respeito às indicações das cactáceas epífitas e seus forófitos apresentadas para a área, fonte valiosa para programas de recuperação florestal, uma vez que Cactaceae constitui a sexta família de Angiospermas mais representativa no modo de vida epifítico na Floresta Atlântica (Freitas et al., 2016).

A conservação das espécies da família em fragmentos florestais localizados em centros urbanos é de grande importância na manutenção da biodiversidade local. Essas cactáceas fornecem recursos alimentares a uma ampla variedade de polinizadores graças à diversidade floral apresentada pela família (Cardoso et al., 2019), e seus frutos são também responsáveis pelo fornecimento de alimentos aos dispersores (Guaraldo et al., 2013; Koski et al., 2018), potenciais aceleradores do processo de regeneração florestal (Corlett; Hau, 2020).

\section{Conclusão}

Reconhecida pelos serviços ecossistêmicos que oferece, o Morro do Moreno ainda não havia sido alvo de estudo taxonômico. Em um contexto amplo, nosso estudo funciona como documento de apoio para apontar a capacidade de colonização de áreas em regeneração, bem como a redução populacional de espécies de Cactaceae causada pelo uso desordenado. Salienta também como fragmentos pequenos, comuns na Região Metropolitana de Vitória, ainda comportam espécies ameaçadas de extinção pouco registradas no estado, 
e ressalta a importância da realização de estudos nessas áreas. Novos estudos acerca de Cactaceae em áreas de encosta inseridas em matriz urbana são necessários, a fim de consolidar ações dentro de planos nacionais de conservação. A efetiva criação de uma Unidade de Conservação no Morro do Moreno com gestão realizada por um órgão ambiental, junto ao correto manejo das espécies exóticas, fiscalização das atividades realizadas na área e limitação dos locais de acesso aos visitantes é de extrema importância, garantindo assim a manutenção da biodiversidade local.

\section{Agradecimentos}

Os autores agradecem à Dra. Daniela Zappi e ao revisor anônimo pelas valiosas sugestões no manuscrito. Agradecem também a Ma. Lígia Ramos dos Santos e Luis Felipe da Silva Zuñe Castañeda, pela revisão inicial dos resumos em francês e espanhol, respectivamente.

\section{Financiamento}

Os autores declaram não haver fontes de financiamento a informar.

\section{Contribuições de autoria}

Conceitualização: WCC, RTV, VFD, LDT. Curadoria de dados: WCC. Investigação: WCC, RTV. Metodologia: WCC. Administração do projeto: WCC. Recursos: LDT, VFD. Programas: RTV. Supervisão: LDT, VFD. Visualização: WCC. Redação - rascunho original: WCC. Redação revisão e edição: LDT, RTV, VFD.

\section{Conflito de interesses}

Os autores declaram não haver conflitos de interesse a informar.

\section{Disponibilidade dos dados}

Os dados integrais analisados durante o estudo atual estão apresentados no corpo do manuscrito.

\section{Conformidade ética}

Não se aplica.

\section{Referências}

Alvares CA, Stape JL, Sentelhas PC, Moraes Gonçalves JL, Sparovek G. Köppen's climate classification map for Brazil. Meteorologische Zeitschrift 2013;22(6):711-728. doi: 10.1127/09412948/2013/0507

Anderson EF. The cactus family. Portland: Timber Press; 2001.

Assis AM, Thomaz LD, Pereira OJ. Florística de um trecho de floresta de restinga de Guarapari, Espírito Santo, Brasil. Acta Botanica Brasilica 2004;18(1):191-201. doi: 10.1590/S0102$\underline{33062004000100016}$

Barthlott W, Taylor NP. Notes towards a monograph of Rhipsalideae (Cactaceae). Bradleya 1995;13:43-79. doi: $10.25223 /$ brad.n13.1995.a7
BFG - Brazilian Flora Group. Growing knowledge: an overview of Seed Plant diversity in Brazil. Rodriguésia 2015;66(4):1.0851.113. doi: $10.1590 / 2175-7860201566411$

Bonnel A, Lavoranti OJ, Curcio GR. Epífitos vasculares no Corredor de Biodiversidade Araucária, bacia do rio Iguaçu, Paraná, Brasil. Cadernos da Biodiversidade 2009;6(2):49-70.

BPBES - Plataforma Brasileira de Biodiversidade e Serviços Ecossistêmicos. $1 .^{\circ}$ Diagnóstico brasileiro de biodiversidade \& serviços ecossistêmicos. São Carlos: Cubo; 2019.

Brasil. Resolução n. ${ }^{2}$ 29, de 7 de dezembro de 1994 - Define vegetação primária e secundária nos estágios inicial, médio e avançado de regeneração da Mata Atlântica e de se definir o corte, a exploração e a supressão da vegetação secundária no estágio inicial de regeneração da Mata Atlântica no Estado do Espírito Santo. Diário Oficial da União 1994;248:21.349-21.350.

Calvente AM. Filogenia molecular, evolução e sistemática de Rhipsalis (Cactaceae). Tese [Doutorado em Botânica] - Universidade de São Paulo; 2010.

Calvente A, Andreata, RHP. The Cactaceae of the Natural Municipal Park of Prainha, Rio de Janeiro, Brazil: taxonomy and conservation. Journal of the Botanical Research Institute of Texas 2007;1(1):529-548.

Calvente AM, Freitas MF, Andreata RHP. Listagem, distribuição geográfica e conservação das espécies de Cactaceae no estado do Rio de Janeiro. Rodriguésia 2005;56(87):141-162. doi: $\underline{10.1590 / 2175-78602005568711}$

Cardoso WC, Calvente A, Dutra VF, Sakuragui CM. Anthropic pressure on the diversity of Cactaceae in a region of Atlantic Forest in Eastern Brazil. Haseltonia 2018;24:28-35. doi: $\underline{10.2985 / 026.024 .0105}$

Cardoso WC, Calvente A, Almeida OJG, Sakuragui CM. Floral biology of cacti and ecological implications. In: Santos MR. Cacti: ecology, conservation, uses and significance. Nova York: Nova Science Publishers; 2019. p. 57-78.

Ceballos SJ. Vascular epiphyte communities in secondary and mature forests of a subtropical montane area. Acta Oecologica 2020;105:1-7. doi: 10.1016/j.actao.2020.103571

CNCFlora [Internet]. Lista Vermelha da Flora do Brasil, continuamente atualizada. [acesso em 29 dez 2019]. Disponível em: http://cncflora.jbrj.gov.br/portal/pt-br/listavermelha

Corlett RT, Hau BCH. Seed dispersal and forest restoration. In: Elliott S, Kerby J, Blakesley D, Hardwick K, Woods K, Anusarnsunthorn V. Forest restoration for wildlife conservation. Chiang Mai: International Tropical Timber Organization \& The Forest Restoration Research; 2020. p. 317-325.

Colodete MF, Pereira OJ. Levantamento florístico da restinga de Regência, Linhares/ES. Revista Brasileira de Biociências 2007;5 (2):558-560.

Conservação Internacional. Hotspots revisitados: as regiões mais ricas e ameaçadas do planeta. Belo Horizonte: Conservação Internacional do Brasil; 2005.

Cullmann W, Götz E, Gröner G. The encyclopedia of cacti. Portland: Timber Press; 1986.

Fabris LC, Cesar O. Estudos florísticos em uma mata litorânea no sul do estado do Espírito Santo, Brasil. Boletim do Museu de Biologia Professor Mello Leitão (Nova Série) 1996;5:15-46.

Fraga CN, Formigoni MH, Chaves FG (Orgs.). Fauna e flora ameaçadas de extinção no estado do Espírito Santo. Santa Teresa: Instituto Nacional da Mata Atlântica; 2019.

Freitas L, Salino A, Menini Neto L, Almeida TE, Mortara SR, Stehmann JR, Amorim AM, Guimarães EF, Coelho MN, Zanin A, Forzza RC. A comprehensive checklist of vascular epiphytes of the Atlantic Forest reveals outstanding endemic rates. PhytoKeys 2016;58:65-79. doi: $10.3897 /$ phytokeys.58.5643

Gorelick R. What is a cephalium? Bradleya 2016;34:100-124. 
Groot SJ. Collecting and processing cacti into herbarium specimens, using ethanol and others methods. Systematic Botany 2011;36(4):981-989. doi: 10.1600/036364411X604985

Guaraldo AC, Boeni BO, Pizo MA. Specialized seed dispersal in epiphytic cacti and convergence with mistletoes. Biotropica 2013;45(4):465-473. doi: 10.1111/btp.12041

Hunt D, Taylor N, Charles G. The New Cactus Lexicon: descriptions and illustrations of the cactus family, vols. 1-2. Milborne Port: David Hunt Books; 2006.

INMET [Internet]. Normais climatológicas do Brasil. [acesso em 23 jul 2020]. Disponível em: http://www.inmet.gov.br/portal/ index.php? $\mathrm{r}=$ clima $/$ normaisClimatologicas

IUCN [Internet]. The IUCN Red list of threatened species. Version 2019-3. [acesso em 29 dez 2019]. Disponível em: https:// www.iucnredlist.org

Koski DA, Valadares RT, Barreto-Lima AF. Fruits in the lizard's menu: consumption of Coleocephalocereus fluminensis (Cactaceae) by Tropidurus torquatus (Tropiduridae). Herpetology Notes 2018;11:853-855.

Leite VR, Lopes TS, Pereira OJ. Florística do ecótono floresta de Restinga e Mata Atlântica de Tabuleiro no município de Serra (ES). Revista Brasileira de Biociências 2007;5(2):483-485.

Luber J, Oliveira MIU, Ferreira MFS, Carrijo T'T. Flora do Espírito Santo: Campomanesia (Myrtaceae). Rodriguésia 2017;68(5):1.7671.790. doi: $10.1590 / 2175-7860201768514$

Mauseth J. Structure-function relationships in highly modified shoots of Cactaceae. Annals of Botany 2006;98: 901-926. doi: $10.1093 / \mathrm{aob} / \mathrm{mcl} 133$

Mayta L, Molinari-Novoa EA. L'intégration du genre Leuenbergeria Lodé dans sa propre sous-famille, Leuenbergerioideae Mayta \& Mol. Nov., subfam.nov. Succulentopi@2015;12:6-7.

Monteiro MM, Giaretta A, Pereira OJ, Menezes LFT. Composição e estrutura de uma restinga arbustiva aberta no norte do Espírito Santo e relações florísticas com formações similares no Sudeste do Brasil. Rodriguésia 2014;65(1):061-072. doi: 10.1590/S217578602014000100005

Pereira OJ, Thomaz LD, Araújo DSD. Fitossociologia da vegetação de ante dunas da restinga de Setiba/Guarapari e em Interlagos/ Vila Velha, ES. Boletim do Museu de Biologia Mello Leitão (Nova Série) 1992;1:65-75.

Pereira OJ, Araújo DSD. Estrutura da vegetação de entre moitas da formação aberta de Ericaceae no Parque Estadual de Setiba, ES. In: Esteves FA. (Ed.). Estrutura, funcionamento e manejo de ecossistemas brasileiros. Rio de Janeiro: Oecologia Brasiliensis; 1995. p. 345-457.

Pereira OJ, Assis AM. Florística da restinga de Camburi, Vitória, ES. Acta Botanica Brasilica 2000;14(1):99-111. doi: 10.1590/ S0102-33062000000100009

Porembski S. Tropical inselbergs: habitat types, adaptive strategies and diversity patterns. Revista Brasileira de Botânica 2007;30 (4):579-586. doi: 10.1590/S0100-84042007000400004

Radford AE, Dickison WC, Massey JR, Bell CR. Vascular plant systematics. New York: Harper and Row; 1974.

Ruschi A. Fitogeografia do estado do Espírito Santo - considerações gerais sobre a distribuição da flora no estado do Espírito Santo. Boletim do Museu de Biologia Professor Mello Leitão (Série Botânica) 1950;1:1-354.

Saiter FZ, Dan ML, Thomaz LD. Floristic and structure of a secondary urban forest with a long history of man-made disturbances in Espírito Santo state, Brazil. Brazilian Geographical Journal: Geosciences and Humanities research medium 2011;2(1):69-85.

Santos LGR, Griffo CLS, Silva AG. Estrutura da vegetação arbustivo-herbácea de um afloramento rochoso da ilha de Vitória, Espírito Santo, sudeste do Brasil. Natureza online 2010;8(1):14-23.

SOS Mata Atlântica, INPE. Atlas dos remanescentes florestais da Mata Atlântica - período 2017-2018. Relatório técnico. São Paulo: Fundação SOS Mata Atlântica \& Instituto Nacional de
Pesquisas Espaciais; 2019. [acesso em 30 dez 2019]. Disponível em: https://www.sosma.org.br/sobre/relatorios-e-balancos

Taylor N. Cactaceae. In: Oldfield S (Ed.). Cactus and succulent plants - status survey and conservation action plan. Gland, Switzerland; Cambridge, UK: IUCN/SSC Cactus and Succulent Specialist Group; 1997. p. 17-20.

Taylor N, Zappi D. Cacti of eastern Brazil. Richmond: Royal Botanic Gardens; 2004.

Vasconcelos LVF, Gonzaga, DR, Reis RCC. Cactaceae no Parque Estadual da Serra da Tiririca, Rio de Janeiro, Brasil. Rodriguésia 2019;70:e02832017. doi: 10.1590/2175-7860201970020

Verçoza FC, Bastos MS. Bromeliaceae e Cactaceae dos afloramentos rochosos do Costão de Itacoatiara, Parque Estadual da Serra da Tiririca, Niterói, Rio de Janeiro, Brasil. Natureza on line 2013;11(1):7-11.

Vila Velha. Lei complementar n. ${ }^{\circ}$ 65, de 9 de novembro de 2018. Institui a revisão decanal da lei municipal n. ${ }^{\circ} 4575 / 2007$ que trata do plano direto municipal no âmbito do município de Vila Velha e dá outras providências. [Internet]. Prefeitura Municipal de Vila Velha. 12 nov 2018 [acesso em 6 jan 2020], Disponível em: http://www.vilavelha.es.gov.br/legislacao/Arquivo/ Documents/legislacao/html/C652018.html\#a370

Zappi D. Pilosocereus (Cactaceae): the genus in Brazil. England: Succulent Plant Research; 1994.

Zappi D, Taylor N, Ribeiro-Silva T, Machado M (Orgs.). Plano de ação nacional para a conservação das cactáceas. Brasília: Instituto Chico Mendes de Conservação da Biodiversidade; 2011.

Zappi D, Taylor N. [Internet]. Cactaceae in Flora do Brasil 2020. [acesso em 6 jan 2020]. Disponível em: http:/ / floradobrasil.jbrj.gov.br/

\section{Cactaceae en un fragmento de bosque urbano de Vila Velha, Espírito Santo, Brasil}

Cactaceae es una familia casi exclusivamente endémica del Nuevo Mundo. En el estado de Espirito Santo, Brasil, la familia se encuentra poco muestreada e inventarios florísticos de sus representantes son escasos. El objetivo de este trabajo fue realizar la flora de especies de Cactaceae que se encuentran en un fragmento urbano antropizado en el Bosque Atlántico en Espirito Santo. Se realizaron excursiones quincenales entre agosto de 2011 y julio de 2012. Se encontraron nueve especies de Cactaceae pertenecientes a siete géneros. Tres de las especies son endémicas del Bosque Atlántico y dos son citadas como amenazadas de extinción, una de ellas registrada en Espirito Santo por primera vez después de una brecha de aproximadamente un siglo. Nuestros datos destacan la importancia de la conservación del fragmento de bosque y la necesidad de estudios sobre la familia en otras regiones del estado. Presentamos una clave taxonómica ilustrada, descripciones, comentarios sobre la taxonomía, distribución geográfica y ecología de las especies, además de la conservación de sus poblaciones en el área.

Palabras clave: Cactus. Flora de Espirito Santo. Bosque Atlántico. Este de Brasil. 


\section{Cactaceae dans un fragment de forêt urbaine} de Vila Velha, Espírito Santo, Brésil

Les Cactaceae sont une famille presque exclusivement du Nouveau Monde. Dans l'État d'Espirito Santo, au Brésil, la famille est mal échantillonnée et inventaires des fleurs de leurs représentants sont rares. l'objectif était de réaliser la flore des espèces de Cactaceae présentes dans un fragment urbaine anthropisé dans la Forêt Atlantique à Espirito Santo. Des excursions ont eu lieu à chaque 15 jours entre août 2011 et juillet 2012. Ont été trouvées neuf espèces des Cactaceae appartenant à sept genres. Trois de ces espèces sont endémiques à la Forêt Atlantique et deux sont citées comme menacée, l'une d'entre elles étant enregistrée pour Espirito Santo pour la première fois après une interruption d'environ un siècle. Nos données soulignent l'importance de la conservation du fragment de forêt et la nécessité d'études sur la famille dans d'autres régions de l'État. Nous présentons une clé taxonomique illustrée, des descriptions, des commentaires sur la taxonomie, la répartition géographique et l'écologie des espèces, en plus de la conservation de leurs populations dans la zone.

Mots clés: Cactus. Flore du Espirito Santo. Forêt Atlantique. Est du Brésil. 